\title{
Editorial: Submarine Groundwater Discharge: Impacts on Coastal Ecosystem by Hidden Water and Dissolved Materials
}

\begin{abstract}
Henrietta Dulai ${ }^{1 *}$, Isaac R. Santos ${ }^{2,3}$, Makoto Taniguchi $^{4}$, Ryo Sugimoto ${ }^{5}$, Jun Shoji ${ }^{6}$ and Abhijit Mukherjee $^{7}$

${ }^{1}$ Department of Earth Sciences, School of Ocean Earth Science and Technology, University of Hawai'i at Manoa, Honolulu, HI, United States, ${ }^{2}$ Department of Marine Sciences, University of Gothenburg, Gothenburg, Sweden, ${ }^{3}$ National Marine Science Centre, School of Environment, Science and Engineering, Southern Cross University, Coffs Harbour, NSW, Australia, ${ }^{4}$ Research Institute for Humanity and Nature, Kyoto, Japan, ${ }^{5}$ Research Center for Marine Bioresources, Fukui Prefectural University, Obama, Japan, ${ }^{6}$ Atmosphere and Ocean Research Institute, The University of Tokyo, Bunkyo, Japan, ${ }^{7}$ Indian Institute of Technology Kharagpur, Kharagpur, India
\end{abstract}

Keywords: Submarine groundwater discharge, coastal hydrology, geochemistry, trophic food webs, coastal contamination, radium, nitrogen, silicon

Editorial on the Research Topic

Submarine Groundwater Discharge: Impacts on Coastal Ecosystem by Hidden Water and Dissolved Materials

\section{OPEN ACCESS}

Edited and reviewed by: Björn Vinnerås,

Swedish University of Agricultural Sciences, Sweden

${ }^{*}$ Correspondence: Henrietta Dula hdulaiov@hawaii.edu

Specialty section: This article was submitted to Water and Wastewater Management,

a section of the journal

Frontiers in Environmental Science

Received: 15 November 2020 Accepted: 08 December 2020

Published: 20 January 2021

Citation:

Dulai H, Santos IR, Taniguchi M, Sugimoto $R$, Shoji $J$ and Mukheriee $A$

(2021) Editorial: Submarine Groundwater Discharge: Impacts on Coastal Ecosystem by Hidden Water and Dissolved Materials.

Front. Environ. Sci. 8:629509.

doi: 10.3389/fenvs.2020.629509
This Research Topic advances our understanding of submarine groundwater discharge (SGD), a hydrological process involving the discharge of terrestrial freshwater combined with the exchange of seawater along coastal margins (Burnett et al., 2003). SGD occurs worldwide and has a range of impacts including its role in shifting ecosystems' ecological states on local scales (Lecher and Mackey, 2018) or contributing greenhouse gases with global implications (Lecher et al., 2015; Sadat-Noori et al., 2016). In spite of remaining unknowns, this Research Topic takes us a step closer, through methodological improvements in SGD quantification, to understanding the contribution of SGD to coastal nutrient and chemical balances, and the effects these chemical subsidies have on coastal trophic food webs. Finally, a review paper synthesizes progress in SGD research over the last decade, including a focus on its economical and cultural values.

\section{METHODOLOGICAL IMPROVEMENTS AND NUTRIENT FLUX CHARACTERIZATION}

Four papers are devoted to refining methods of quantification of SGD. A common indirect approach of quantifying SGD rates is to apply a mass balance of a chemical with concentration in groundwater exceeding those in seawater. Lamontagne and Webster caution that inadequate sampling focusing on surface water only when vertical mixing is slow may lead to biased SGD estimates. Short-lived radium $(\mathrm{Ra})$ isotope distributions revealed that slow vertical mixing creates vertical gradients that need to be accounted for when building mass balance models.

Tamborski et al. apply naturally occurring Ra isotopes in a semi-enclosed basin to estimate SGD and associated nutrient fluxes. Because the four Ra isotopes have different ingrowth rates, they are sensitive to different time-scale processes. Specifically, short-lived Ra isotopes trace short-scale SGD 
processes such as wave or tidal pumping, and their mass balance is also sensitive to contributions from sediments in addition to SGD. In contrast, long-lived Ra isotope mass balances are highly sensitive to fluxes at the boundaries of the study domain and less sensitive to short- and small-scale SGD.

Oehler et al. revisit the use of dissolved silicon (DSi) as SGD tracer. DSi becomes enriched in groundwater due to biogenic silica dissolution and water-rock interactions. Depending on the hydrogeologic settings, DSi can trace terrestrial and brackish SGD or can be used as a tracer for marine SGD. They emphasize that DSi is a nutrient and may exhibit non-conservative behavior in the coastal ocean. A large improvement in DSi application is a recent progress in its chemical analysis that allows measurements from 1-ml sample volumes. This helps with the recurring problem of end-member characterization, especially from lowvolume pore water samples.

Characterization of SGD and nutrient fluxes from coastal karst aquifers was the focus of Bejannin et al. SGD estimates in karstic coastlines are difficult due to the combined presence of different water sources that include springs, pore water exchange, and rivers. Horizontal eddy diffusivity from offshore ${ }^{224} \mathrm{Ra}$ transects and nutrient gradients were used to derive SGD nutrient fluxes. With this approach, the authors bypass the need for an exact characterization of the SGD endmember, minimizing uncertainties. However, this method is only applicable when the SGD tracers and nutrients behave conservatively within the timeframe of coastal mixing and have no significant external sources.

\section{ANTHROPOGENIC CHEMICAL SIGNATURES IN SUBMARINE GROUNDWATER DISCHARGE}

It has long been recognized that SGD is a significant source of nutrients to the coastal ocean. Over the last decades progress has also been made on characterizing the origin of nutrients in SGD, mainly implicating anthropogenic sources. However, in many settings single tracing techniques alone cannot discriminate between sources. Tamborski et al. used boron (B) and boron isotopes $\left(\delta^{11} \mathrm{~B}\right)$ in combination with $\delta^{15} \mathrm{~N}$ and $\delta^{18} \mathrm{O}$ to trace sources of $\mathrm{NO}_{3}{ }^{-}$to two subterranean estuaries and constrain end-member isotopic signatures. They concluded that $\delta^{15} \mathrm{~N}$ and $\delta^{18} \mathrm{O}$ in $\mathrm{NO}_{3}{ }^{-}$alone could not differentiate nitrogen sourced from septic waste, fertilizer and precipitation. However, $\delta^{11} \mathrm{~B}$ revealed that the STE was affected by agricultural fertilizer inputs and $\mathrm{N}$ was predominantly sourced from nitrification of ammonium.

Nutrients are not the only anthropogenically sourced chemicals in SGD. Welch et al. studied legacy and currentlyused pesticides in groundwater, stream baseflow, and SGD in an oceanic island. SGD and baseflow carried as much as $1 \mathrm{~g}$ of glyphosate and $9 \mathrm{~g}$ of DDT per day into Faga'alu Bay. While glyphosate is currently widely applied and its presence in groundwater is not surprising, the persistence of DDT in groundwater is noteworthy since it has been phased out in the 1970s. The sustained flux of glyphosate and DDT via SGD could have chronic effects on reef health and should be investigated in more detail. These observations shed light into the role of SGD as an overlooked source of contaminants of emerging concerns to the coastal ocean.

\section{SUBMARINE GROUNDWATER DISCHARGE SUPPORTS BIOLOGICAL PRODUCTIVITY}

SGD-derived nutrients sustain primary production, which in turn increases food availability to higher trophic levels. Andrisoa et al. showed that mussel growth rates and condition is greater at groundwater exposed sites. High growth rates were the consequence of both the higher winter temperatures moderated by groundwater discharging at constant temperatures, and groundwater-derived nutrient supply that increased food availability. This study provides direct evidence for the "downstream" ecological impacts of groundwater discharge on higher trophic levels and that SGD can have a local economic effect.

The propagating effect of SGD along trophic linkages was also explored by Fujita et al. who investigated how SGD enhances the productivity and biomass of producers, primary consumers, and secondary consumers. Carbon stable isotopes revealed that nutrients from terrestrial SGD were utilized by juvenile marbled sole. Fish biomass across three sites in the western North Pacific were also related to high SGD locations.

Starke et al. argue that apart from nutrient inputs, temperature should also be considered to drive fish distribution around fresh SGD sites in the tropics, perhaps due to the higher oxygen content of colder water. They demonstrated that fish are attracted to SGD sites using a biofouling experiment. The enhanced settlement of filamentous sessile algae near SGD sites became the food source attracting fish. The results presented showed that submarine springs attract fish in tropical settings and represent some of the first manipulative experiments in the SGD context.

\section{REVIEW OF THE STATUS QUO}

The recent advances in the field are highlighted in a review by Taniguchi et al. The field has now entered a "mature stage" with a large number of research groups exploring the multiple hydrological, geochemical, biological, and oceanographic facets of SGD. The review includes updates on technological advances of SGD measurement, description of geophysical drivers, magnitudes, and biological effects of SGD and porewater exchange. It is recognized that terrestrial freshwater discharge, processes driven by wave setup and tidal pumping, as well as pore water exchange are not necessarily synergistic or additive. It has also become clear that global fresh SGD only accounts for a minor fraction of river discharge (Luijendijk et al., 2020) while the total (saline + fresh) SGD is often much greater than river inputs (Cho et al., 2018).

The economic and cultural implications of SGD are now finally being evaluated. SGD's role in supporting coastal 
ecosystems and food resources had also had significance in various cultures historically, these cultural values and roles of SGD are being described in the scientific literature.

\section{CONCLUSION}

This collection of studies from multiple parts of the globe including France, Australia, Japan, Pacific Islands, and the USA further illustrates the overall widespread significance of SGD for water, nutrient, and contaminant delivery to the coastal ocean. These papers show improved ways of quantifying the different components of SGD and pore water exchange. Through multiple examples presented here now we also have clearer evidence for the importance of SGD in driving food webs, fish stocks, and therefore indirectly also economies. Multiple challenges however remain, for example, in upscaling SGD to regional and global scales and in better understanding its

\section{REFERENCES}

Burnett, W. C., Bokuniewicz, H., Huettel, M., Moore, W. S., and Taniguchi, M. (2003). Groundwater and pore water inputs to the coastal zone. Biogeochemistry 66 (1-2), 3-33. doi:10.1023/b:biog.0000006066. 21240.53

Cho, H. M., Kim, G., Kwon, E. Y., Moosdorf, N., Garcia-Orellana, J., and Santos, I. R. (2018). Radium tracing nutrient inputs through submarine groundwater discharge in the global ocean. Sci. Rep. 8, 2439. doi:10.1038/s41598-01820806-2

Lecher, A. L., Kessler, J. D., Sparrow, K. J., Kodovska, F. G-T., Dimova, N., Murry, J., et al. (2015). Methane transport through submarine groundwater discharge to the North Pacific and Arctic Ocean at two Alaskan sites. Limnol. Oceanogr. doi:10.1002/lno.10118

Lecher, A., and Mackey, K. (2018). Synthesizing the effects of submarine groundwater discharge on Marine Biota. Hydrology 5 (4), 60. doi:10.3390/ hydrology5040060 temporal variation. For example, with climate change SGD drivers such as precipitation patterns and sea level are changing and we are yet to see how SGD and related water, nutrient, and other chemical fluxes will be affected. But there is progress made in producing more and more representative SGD measurements that provide the baseline on which future studies can build on.

\section{AUTHOR CONTRIBUTIONS}

All authors listed have made a substantial, direct and intellectual contribution to the work, and approved it for publication.

\section{ACKNOWLEDGMENTS}

We thank all authors for their contribution to this Research Topic.

Luijendijk, E., Gleeson, T., and Moosdorf, N. (2020). Fresh groundwater discharge insignificant for the world's oceans but important for coastal ecosystems. Nat. Commun. 11, 1260. doi:10.1038/s41467-020-15064-8

Sadat-Noori, M., Maher, D. T., and Santos, I. R. (2016). Groundwater discharge as a source of dissolved carbon and greenhouse gases in a subtropical estuary. Estuar. Coast. 39 (3), 639-656. doi:10.1007/s12237-015-0042-4

Conflict of Interest: The authors declare that the research was conducted in the absence of any commercial or financial relationships that could be construed as a potential conflict of interest.

Copyright (C) 2021 Dulai, Santos, Taniguchi, Sugimoto, Shoji and Mukherjee. This is an open-access article distributed under the terms of the Creative Commons Attribution License (CC BY). The use, distribution or reproduction in other forums is permitted, provided the original author(s) and the copyright owner(s) are credited and that the original publication in this journal is cited, in accordance with accepted academic practice. No use, distribution or reproduction is permitted which does not comply with these terms. 